\title{
The influence of weather on local geographical patterns of police calls for service
}

\section{Chris Brunsdon}

Department of Geography, University of Leicester, University Road, Leicester LE1 7RH,

England; e-mail: cb179@le.ac.uk

\section{Jonathan Corcoran}

University of Queensland Social Research Centre (UQSRC), Institute of Social Science Research (ISSR), University of Queensland, St Lucia, QLD 4072, Australia; e-mail: jj.corcoran@uq.edu.au

\section{Gary Higgs, Andrew Ware}

Advanced Technology, Computing and Mathematical Sciences, University of Glamorgan,

Pontypridd CF37 1DL, Wales; e-mail: ghiggs@glam.ac.uk, jaware@glam.ac.uk

Received 22 August 2005; in revised form 29 July 2008; published online 17 July 2009

\begin{abstract}
The effect of weather elements on the incidence of different types of crime has been the focus of a number of research studies. However, the detailed geographical dimension of this relationship has been largely ignored. The aim of this paper is to broaden the research on weather and crime to consider the effect of weather parameters on the spatial arrangement of crime within an urban area of the UK. A novel combination of techniques that are capable of both evaluating statistically and visualising geographically the effect of weather variables on the incidence of one type of crime, namely calls for police service for disorder or disturbances, is presented. These techniques are examined in relation to the theories that have traditionally been put forward to explain such trends. We conclude that, in our study area, both temperature and humidity exert significant effects on the spatial patterning of incidents of disorder or disturbances. Rainfall, wind speed, and wind direction were found not to have a significant effect for this type of call for service. More research is needed to see how transferable these findings are to other geographical areas with different climatic regimes.
\end{abstract}

\section{Introduction}

In recent years the popular media have provided a variety of headlines that link weather patterns to fluctuations in the levels of crime; typical examples include "heat wave sparks car break-ins" (BBC News, 2003a); "summer sees peak in violence" (BBC News, 2001); and "warning over warm weather robberies" (BBC News, 2003b). The possibility of a relationship has also been the focus of a number of academic research studies wherein weather has been used to help explain the variation in a wide range of criminal activity - for example, rape and domestic violence (Cohn, 1993), homicide (Cheatwood, 1995), assault (Rotton and Cohn, 2004), and commercial robberies (Van Koppen and Jansen, 1999). Despite the breadth of previous research on weather and crime, detailed geographical dimensions at, for example, intracity levels, have received relatively less attention. It is the intention of this paper to begin to explore this underresearched area and to attempt to redress the gaps in such research. Specifically, we utilise a series of techniques to explore visually the effect of weather parameters on the detailed spatial patterning of police calls for service, and we apply statistical tests to assess whether such elements are statistically significant using detailed disaggregate data for an urban area of the UK.

Despite the volume of anecdotal evidence and academic research which has postulated that weather exerts some influence on the volume of crime, we still know very little as to the effect on the detailed geography of crime. Many questions remain to be answered, such as: 
- Do increases in temperature bring about changes in where crime is committed?

- Is it simply the same locales that are subject to higher volumes of incidents?

- Does heavy rain act as a dampener on certain types of crime? If so, is this geographically discernable?

- Are such trends replicable for different climatic regimes?

The primary aim of this paper is to present a novel combination of techniques that is capable of evaluating statistically, and visualising geographically the effect of weather variables on the incidence of police calls for service at the microlevel. Here, the microlevel is defined as point data for an incident (each crime containing an $x, y$ coordinate) and hourly weather data for each meteorological parameter.

The remainder of this paper is structured as follows. In section 2 we briefly review previous research that has applied geographical and GIS-based techniques to the analysis of crime data, along with criminological theory that can be used to justify the identified patterning. We draw on this literature to highlight the need for research which explores the effect of weather on the geographical patterning of crime. In section 3 we review previous research that has looked at the influence of weather on crime, the preliminary conclusions drawn, and the geographic granularities of the studies. In the fourth section of the paper we describe the datasets used in our study area and provide a discussion of the statistical and visualisation methods that are applied to the data. Results from the analysis are presented in section 6, followed by their discussion in section 7. In the final section of the paper we summarise the findings before highlighting a number of potential avenues for further investigation.

\section{Spatial approaches to analysing crime}

Early interest in the spatial dimension of crime dates back to the 19th century (Guerry, 1833; Quètelet, 1842), when cartographic techniques were utilised to visualise and analyse crime information. The role of geography and the criminology of place have received growing attention in recent years (Eck and Weisburd, 1995). In particular there have been several texts concerned with applying GIS-based analysis to crime data in different application areas, such as hot-spot analysis, geographical profiling, or crime displacement following crime-prevention strategies [see, for example, texts by Boba (2005); Chainey and Ratcliffe (2005); Goldsmith et al (2000); Harries (1999); Hirschfield and Bowers (2001); Leipnik and Albert (2003); Weisburd and McEwen (1995)]. The prevalence of crime mapping among both practitioners and researchers has been recognised with the establishment of the US-based MAPS research centre (Mapping and Analysis for Public Safety, formerly known as the Crime Mapping Research Center) in 1997 (http://www.ojp.usdoj.gov/nij/maps/), and the UK Jill Dando Institute of Crime Science in 2000 (http://www.jdi.ucl.ac.uk/). These centres additionally host two crime-mapping conferences that attract both practitioners and academics interested in applying spatial techniques in crime applications. The operational use of crime-mapping technologies has been noted by surveys both in the US (Mamalian and LaVigne, 1999) and in the UK (Corcoran and Ware, 2002). A recent guide from the UK Home Office (2005) underlines the importance of crime mapping in operational contexts in presenting to frontline officers situations in which it can be used to assist in a range of policing activities.

The advent and development of GIS technologies and the increased availability and quality of spatially disaggregate data have undoubtedly fuelled the development of a range of crime-mapping and spatial analysis techniques. These techniques have facilitated the efficient mapping and spatial exploration of geocoded crime data, thereby enabling the role of place (such as a particular street or building complex) to be examined. In particular, Anselin et al (2000) put forward two powerful GIS 
facilities - flexible spatial aggregation tools and simply contiguity matrices for representing neighbour relationships between different area units-which are useful in such regards. In addition, a number of commercial GIS packages now incorporate techniques such as 'hot spotting' or tracking analysis (for example, the Hot Spot analysis tool in ArcGIS9) extensions to enhance their functionality.

Other researchers in this area have been concerned with putting forward theoretical explanations for such trends. These have included the promotion of three principal theories-namely, routine activities theory-RA theory (Cohen and Felson, 1979), crime pattern theory (Brantingham and Brantingham, 1993), and rational choice theory (Cornish and Clarke, 1986) - termed 'place-based theories' (Anselin et al, 2000), whereby the objective is to derive an understanding of the mechanisms that influence and control individual actions. RA theory has been one of the principal theoretical explanations for the effect of weather on crime. This theory purports that, for a crime to occur, three fundamental factors need to coincide in time and spacenamely, "motivated offenders, suitable targets and absence of capable guardians against violation" (Cohen and Felson, 1979, page 589). In this study we use calls for police service, which are not recorded crimes (as stipulated in RA theory); however, previous studies have successfully applied RA theory to police incidents in order to derive an explanation of the observed patterning (see, for example, Bowers and Hirschfield, 1999; Cohn, 1996; Sherman et al, 1989). In this paper we use reported acts of disorderly conduct, whereby motivated offenders are those individuals committing a disorder or disturbance, suitable targets are those localities in which the disorderly behaviour occurs, and guardianship can be defined either as formal controls, such as police patrols, or as informal controls, such as friends. RA theory states that individuals follow strict routines within which certain opportunities and risks are present in respect to criminal activities. In this paper we explore the hypothesis that weather has the potential to modify these strict routines whereby individuals may choose to partake in nontypical activities in response to changes in weather conditions, and, as a result, may either heighten or lower the incidence of disorderly conduct. For example, particularly warm weather encourages more individuals to use outdoor spaces such as public parks and outdoor recreation areas. As such, this modifies the three components that constitute RA theory, creating the potential for more motivated offenders, an increase in the number of suitable targets, and a reduction in the amount of guardianship.

From the RA perspective the notion of locality (and time) is central in comprehending the mechanics and patterning of criminal activity. To explore this theme the application of GIS tools can be used to identify salient criminogenic characteristicssuch as a concentration of criminal damage in close proximity to entertainment establishments, for example. The work of Sherman et al (1989) was an early example of how GIS tools were used to identify crime hot spots. Using twelve months of calls for police service data for Minneapolis, they found that only 3.3\% of addresses were the subject of $50.4 \%$ of calls, which demonstrates the spatial skewness of crime, and more importantly they identified those high crime places that may be the subject of further investigation in order to help understand the complex dynamics of crime.

There are now a variety of freely available software packages that are capable of conducting spatial computations, including CrimeStat, GeoDa, and SaTScan [for a more comprehensive review of these packages see, for example, Anselin (2004)]. Techniques to analyse spatial distribution range in complexity, from simple descriptions of coverage (eg the calculation of mean centre, standard deviation of the $x$ and $y$ coordinates, and minimum bounding area), to more complex computations (eg the degree of spatial autocorrelation and identification of clustering). The statistical 
evaluation of the spatial arrangement of crime is an area that has received much attention. For the assessment of point data, for example, the nearest-neighbour statistic (NN) (Clark and Evans, 1954) is a commonly used technique. The NN statistic compares the mean distance between points to that of an expected distance (on the basis of a random distribution). An NN statistic of $<1$ indicates clustering, $>1$ indicates dispersion, and values around 1 signify a random distribution. In a recent application to crime data, Ratcliffe (2005) applied the NN statistic, combined with Monte Carlo simulation, to identify movements of spatial patterns over time following a burglary reduction campaign in Canberra, Australia. Here, the NN statistic was applied to burglary data for periods before and after a targeted police burglary initiative in an attempt to identify evidence of spatial displacement. As suggested by Ratcliffe (2005), the use of point analysis techniques overcomes some of the problems inherent in using area-based data, such as the modifiable areal unit problem. In another application, Rogerson and Sun (2001) used the NN statistic coupled with the cumulative sum methods to detect changes in spatial patterns over time with arson data.

A popular technique using aggregate crime data is the calculation of spatial autocorrelation. This test assesses the degree to which areas are correlated to one another. In the context of crime data a positive spatial autocorrelation refers to the situation in which locales of high incidence adjoin other areas of similar high incidence. Both the Moran $I$ (Moran, 1950) and Geary $C$ (Geary, 1954) indices offer a measure for spatial autocorrelation that can prove useful in terms of assessing global trends. A local form of the Moran $I$, in which the statistic is applied to individual zones, has been developed by Anselin (1995). The local Moran I is a LISA (local indicator of spatial association) statistic (Anselin, 1995), where the objective is to derive a localised estimate of connectivity and to assess the degree to which it deviates from spatial randomness. The local form of Moran I (Anselin, 1995) can provide a useful comparison to global estimates. Murray et al (2001), for example, applied this statistic to property crime in Brisbane in order to identify those suburbs with significant values, and showed that there was positive spatial autocorrelation around the city centre.

Identifying hot spots of crime is one of the fundamental processes in understanding the spatial dynamics of crime in an area. One technique that has been widely applied to the identification of hot spots in crime data is standard deviation ellipses (see, for example, Canter, 1998; Hirschfield and Bowers, 1997). In addition to the use of such techniques as a depiction tool, centrographic measures (such as angle of rotation and coefficient of circularity) have been added to supplement their utility (Langworthy and Jefferis, 2000). Bowers et al (2004) have explored the use of a variety of techniques to produce 'prospective' hot-spot maps in order to examine areas of elevated risk of victimisation to residential burglary. Ratcliffe (2004) extended this to include temporal variations in crime patterns and produced a typology of temporal and spatial hot-spot scenarios that could be used to guide appropriate policing strategies.

A second technique that has become an increasingly popular way to identify hot spots of crime is kernel density estimation (KDE) (Silverman, 1986). Studies that use KDE included those of Ratcliffe (2000), Chainey (2002), and Brunsdon et al (forthcoming). Whereas standard deviation ellipses represent hot spots as simple geometric shapes, KDE is capable of identifying irregularly shaped hot spots, which are more accurately defined (McLafferty et al, 2000). The degree of flexibility that KDE offers (for example, the options to determine class boundaries) allows the analyst to significantly influence the visual depiction of the data. Chainey et al (2002) attempt to consolidate some of these decision criteria by offering a formalised procedure by which statistically robust surface mapping can be consistently produced. Although there has 
been an increasing emphasis on the use of spatial analytical techniques in crime mapping, there has been much less research that has applied such techniques in order to examine the potential influence of the weather on crime patterns. In this paper we attempt to redress this situation using an analysis of police calls for service for an intraurban case study. First, in the next section, we review the existing body of literature on weather and its effect on human behaviour and, in particular, the patterning of crime.

\section{Previous studies relating weather and crime patterns}

There have been a number of studies that have focused on the influence of weather patterns on human behaviour. Zacharias et al (2001), for example, investigated the impact of microclimatic conditions (namely temperature, sun, and wind speed) in a business district on utilisation patterns of open spaces, concluding that increases in temperature result in the greater use of such places. Gatrell and Bierly (2002) demonstrated the effect of weather on voter behaviour, wherein wet weather and low temperatures inhibit voter turnout. Other meteorological conditions are also reported to exert influences on our behaviour, such as atmospheric pressure, sunshine, relative humidity, and wind speed. Similarly, a number of studies have focused on both the direct and indirect impacts of weather conditions on a range of health outcomes [see, for example, Sulman (1984) and Patz et al (2000) for reviews of such studies]. Specific examples include the impact of heat waves on mortality and emergency hospital admissions for different medical conditions and population age groups [for example, for London by Kovats et al (2004) and Johnson et al (2005)]. Over longer time periods, Davis et al (2004) examined the seasonality of mortality using monthly data for twenty-eight US cities in relation to climate change over the period 1964-98.

The effect of weather on crime has also been the focus of a number of research studies [see Cohn (1990) and Rotton and Cohen (2002) for reviews of such studies]. These invariably explore the impact of weather on behavioural patterns; it is posited that changes in behaviour can potentially bring about two conditions as far as crime is concerned. Firstly, weather conditions may directly influence an individual to commit a crime when an individual becomes aggressive-owing to excessive temperature, for example [the temperature-aggression (T/A) theory initially proposed by Quètelet (1842)]. An early investigation of the association between temperature and crime was published in The Lancet (Anonymous, 1910, page 1361) for a study of crime in 1908 that suggested that "offences of the impulsive class are directly influenced by variations of temperature." Cohn (1990) noted, from a review of previous studies, that certain types of crime (eg assaults, burglary, and collective violence) increase with temperature. However, for other types of crime the relationship is not so clear-cut. Similarly, when the review was extended to examining the influence of other weather variables (eg sunlight, wind, rainfall) there was little evidence of significant influences on certain types of crime.

The potential relationship between temperature and aggression and violent crime has been the subject of more recent research [see, for example, studies by Anderson and Anderson (1984); Cheatwood (1995); Cotton (1986); Harries et al (1984); Rotton (2004); Rotton and Cohn (2000a); (2000b); (2003); (2004)]. Rotton and Cohn (2002, page 486), for example, from their review of previous studies, conclude that "temperature is the only variable that has consistently emerged as a correlate of criminal activity." The study by Harries et al (1984), concluded that there was a link between heat stress and assault in Dallas (United States), especially in low-status neighbourhoods. This was attributed to the inability of the lower status areas to "buffer themselves from the ambient conditions and from one another" (Harries et al, 1984, page 602). 
Thus levels of assaults and violent crime have been linked to higher temperatures, trends replicated in another US city (Washington, DC), where levels of homicides, rapes, and assaults were found to be correlated with average weekly temperature (Hagelin et al, 1999). The research by Rotton and Cohn (2004) further demonstrated, from a study of calls for service for police in Dallas, that the relationship between temperature and assaults varied over space as well as time.

A second set of explanations for trends suggests that certain weather conditions may lead to situations that can be exploited by criminals - such as windows being left open to maintain comfortable temperatures. By applying RA theory it has been suggested that weather conditions (amongst other factors) have the potential to influence the behavioural patterns of individuals, such as the amount of time they spend outdoors, thereby increasing opportunities for criminal activities and thus influencing the levels of crime experienced. RA theory has been used to help justify the influences of weather on criminal activity - see, for example, Rotton and Cohn (2003). Hipp et al (2004, page 1334), however, suggested that these theories are not necessarily mutually exclusive and that "indeed it is possible that both are at work in some instances." Their study, for example, looked at seasonal patterns in crime rates within US communities (8460 police units) for the time period 1990 - 92 to test the relevance of both of these theoretical explanations for variations in different types of crime (classified into property and violent crimes). In the case of the former they found correlations with warm weather which, they suggest, is consistent with the RA theory. Trends in violent crime tended to support both the RA theory and the T/A theory. Their main conclusion was therefore that "the T/A theory may well have some use in explaining violent crime, but the bulk of our findings on seasonal changes in both violent and property crime can be attributed to RA theory and the fact that the changing behaviour patterns of individuals during mild temperatures increases opportunities for criminal victimization" (Hipp et al, 2004, page 1365). However, the RA theory does not appear to be supportive of trends in other cultural contexts; Yan (2004), for example, notes a lack of seasonality in burglary and total theft in Hong Kong.

In addition to temperature variations, a number of studies have examined the role of other meteorological parameters on crime levels. These have included the potential influence of rainfall patterns (Perry and Simpson, 1987), sunlight hours (Heller and Markland, 1970), atmospheric pressure (Feldman and Jarmon, 1979), and humidity and wind speed (Rotton and Frey, 1985). However, with regard to the potential effect of rainfall, Rotton and Cohn (2002, page 486) concluded that "there is very little support for the idea that rainfall is a police officer's best friend." They also note that there is contradictory evidence on the effects of barometric pressure on crime rates. Table 1 summarises a number of such studies with an emphasis on the geographic granularity of analysis (geographical area and temporal units for weather and crime data) and conclusions drawn. Whereas previous reviews have focused on the weather parameters used and temporal granularity, here geographical granularity forms the principal focus of our study.

Generally, to date, the majority of such studies have been conducted at relatively coarse spatial scales of analysis (eg citywide, regionwide, and nationwide) - notable exceptions include that of Harries et al (1984), who analysed the role of climatic factors on interneighbourhood variations in crime patterns. In a more recent study, Ceccato (2005) analysed the spatiotemporal relationship of weather and homicide in São Paulo at an intraurban scale through the application of the Kulldorff scan test (Kulldorff, 1997). Results indicated that homicide clusters were largely stablehowever an increase in cluster size was noted during holiday periods, and a reduction was found during the winter and spring months. Such studies have tended to use 
Table 1. Examples of previous studies investigating links between weather and crime.

\begin{tabular}{|c|c|c|c|c|c|c|c|}
\hline $\begin{array}{l}\text { Geographical } \\
\text { unit }\end{array}$ & Author(s) & $\begin{array}{l}\text { Time span } \\
\text { examined }\end{array}$ & $\begin{array}{l}\text { Weather type(s) } \\
\text { examined }\end{array}$ & $\begin{array}{l}\text { Crime type(s) } \\
\text { examined }\end{array}$ & $\begin{array}{l}\text { Temporal } \\
\text { unit(s) }\end{array}$ & $\begin{array}{l}\text { Type of } \\
\text { analysis }\end{array}$ & Findings \\
\hline $\begin{array}{l}\text { Nationwide } \\
\text { (England and } \\
\text { Wales) }\end{array}$ & Field (1992) & $\begin{array}{l}\text { forty years of } \\
\text { annual data, } \\
\text { twenty years of } \\
\text { quarterly data, } \\
\text { ten years of } \\
\text { monthly data }\end{array}$ & $\begin{array}{l}\text { temperature, } \\
\text { rainfall, and } \\
\text { sunshine }\end{array}$ & $\begin{array}{l}\text { violence against the } \\
\text { person, sexual } \\
\text { offences, burglary, } \\
\text { criminal damage }\end{array}$ & $\begin{array}{l}\text { monthly, } \\
\text { quarterly } \\
\text { and annually }\end{array}$ & regression & $\begin{array}{l}\text { strong support of a positive } \\
\text { association between } \\
\text { temperature and most property } \\
\text { and violent crimes. Rainfall and } \\
\text { sunshine exhibited no } \\
\text { relationships. }\end{array}$ \\
\hline $\begin{array}{l}\text { Nationwide } \\
\text { (Italy) }\end{array}$ & Preti (1997) & twenty years & $\begin{array}{l}\text { temperature, } \\
\text { humidity, rainfall, } \\
\text { hours of daylight, } \\
\text { sunshine exposure }\end{array}$ & suicide & monthly & $\begin{array}{l}\text { Spearman } \\
\text { correlation }\end{array}$ & $\begin{array}{l}\text { Sunshine exposure was shown } \\
\text { to be the most influential } \\
\text { climate factor and potentially } \\
\text { causal on suicidal behaviour. }\end{array}$ \\
\hline $\begin{array}{l}\text { Nationwide } \\
\text { (Netherlands) }\end{array}$ & $\begin{array}{l}\text { Van Koppen } \\
\text { and Jansen } \\
(1999)\end{array}$ & seven years & $\begin{array}{l}\text { temperature, wind } \\
\text { speed, hours of } \\
\text { sunshine, radiation, } \\
\text { rainfall, atmospheric } \\
\text { pressure }\end{array}$ & $\begin{array}{l}\text { commercial } \\
\text { robbery }\end{array}$ & $\begin{array}{l}\text { daily and } \\
\text { monthly }\end{array}$ & regression & $\begin{array}{l}\text { Weather was not found to } \\
\text { significantly influence the } \\
\text { volume of commercial } \\
\text { robberies. }\end{array}$ \\
\hline Citywide & $\begin{array}{l}\text { Cohn and } \\
\text { Rotton } \\
(2000)\end{array}$ & two years & $\begin{array}{l}\text { temperature, wind } \\
\text { speed, relative } \\
\text { humidity, rainfall, } \\
\text { and cloud cover }\end{array}$ & $\begin{array}{l}\text { burglary, robbery, } \\
\text { and larceny - theft }\end{array}$ & $\begin{array}{l}\text { hourly, } \\
\text { daily, and } \\
\text { monthly }\end{array}$ & $\begin{array}{l}\text { hierarchical } \\
\text { regression }\end{array}$ & $\begin{array}{l}\text { Temperature was found to be a } \\
\text { minor but significant predictor } \\
\text { of property crimes (whilst con- } \\
\text { trolling for temporal variables). }\end{array}$ \\
\hline $\begin{array}{l}\text { Neighbour- } \\
\text { hood }\end{array}$ & $\begin{array}{l}\text { Harries et al } \\
(1984)\end{array}$ & twelve months & temperature & aggravated assault & $\begin{array}{l}\text { daily and } \\
\text { monthly }\end{array}$ & $\chi^{2}$ & $\begin{array}{l}\text { Analysis of structural density, } \\
\text { alcohol consumption, and levels } \\
\text { of deprivation in association } \\
\text { with recorded assaults and } \\
\text { temperature. Some neighbour- } \\
\text { hoods are more vulnerable to } \\
\text { assault through heat stress than } \\
\text { others }\end{array}$ \\
\hline
\end{tabular}


relatively coarse temporal units - for example, monthly, quarterly, or annual records (eg Anderson et al, 1997). Exceptions include the studies by Ceccato (2005), Van Koppen and Jansen (1999), Lab and Hirschel (1988), and Harries et al (1984), all of which used daily weather patterns in their analysis. Van Koppen and Jensen (1999), for example, examined the role of a wider range of factors on commercial-robbery trends within the Netherlands in order to explain possible reasons for daily and weekly peaks. In addition, those studies by Rotton and Cohn (2004) and Cohn and Rotton (2000) used both daily and hourly weather data. In the latter study, for example, Cohn and Rotton (2000) found that both the time of day and the day of week are the best predictors of property offences in Minneapolis. Cohn and Rotton (1997) looked at three-hour measures of temperature and assaults in order to examine the hypothesis that such relationships are stronger during evening hours and at weekends. In an analysis of calls for police service in Chicago, LeBeau and Corcoran (1990) reported a correlation between violence and the evening hours, which were typically the cooler part of the day.

However, whilst there is an increasing body of research that involves the use of spatiotemporal techniques to study crime patterns in general (for example, Ratcliffe, $2000 ; 2002$; 2005), few studies have examined the potential influence of climatic variables on geographical patterns of crime at fine temporal and geographical scales. In regard to the spatial variation of crime with changes in weather, very little has been previously explored. One notable exception is the study by Openshaw et al (1994), who used map animation, $100 \mathrm{~m}$ grid referenced police incidents, and hourly temperature readings to explore the effect of temperature on the incidence of public disorder offences in Newcastle city centre. Each frame of the map animation represented a temperature at which incidences were reported, between $3{ }^{\circ} \mathrm{C}$ and $25^{\circ} \mathrm{C}$. Results suggested that the volume of public disorder incidence increases with temperature; however, they provided little evidence as to the impact on spatial patterning of these incidents-one might expect that during periods of warm conditions disorder will be more dispersed, whilst cooler conditions will bring about a higher geographic concentration in persistent high-crime areas. Despite the fine geographical and temporal granularity of this study, only temperature was explored and no statistical analysis was presented. In our present study we demonstrate the use of statistical analysis and geotemporal visualisation techniques in order to explore such potential linkages. Before describing our detailed methodology, we draw attention to the characteristics of the datasets analysed in this study.

\section{Data sources}

Cohn (1990, page 62), in a review of the relationship between weather and criminal behaviour, drew attention to the importance of good quality data and suggested, in particular, that "the timing of the criminal events that are studied must be as exact as possible, as weather conditions can change between the occurrence of a crime and the time the official report is filed. The most appropriate type of crime data may be calls for service received by police." In this study we have access to detailed disaggregate data in the form of a database of police callouts to reported acts of disorder or disturbance for an urban centre and its surrounding region for a two-year period. For each police callout, a date, a time, and a grid reference was supplied. Calls for police service data are used, and specifically those of the incidence of disorder or disturbance, as the time stamp recorded is likely to be relatively close to the actual time the incident occurred. This is important, as weather conditions are relevant to the time at which the incident occurred. A disorder or disturbance may be described as an incident of antisocial behaviour. Typical examples include general drunkenness, violent 


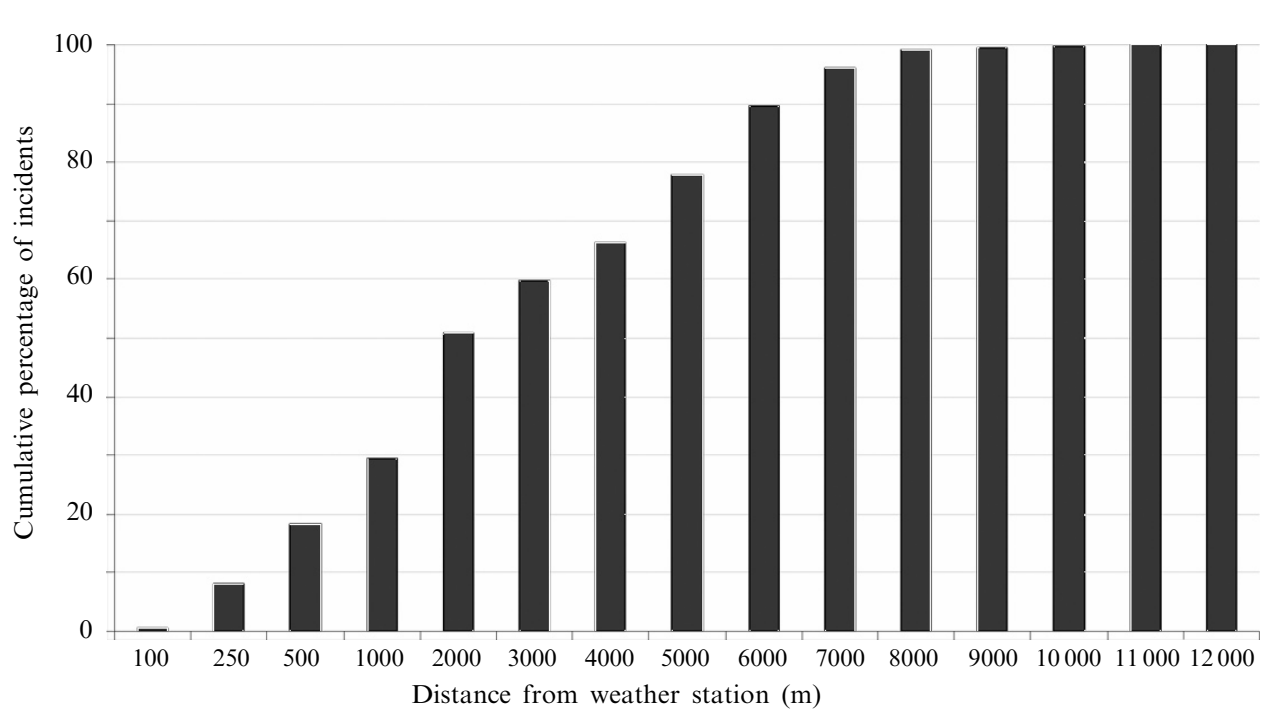

Figure 1. Proximity analysis of the weather station in relation to the spatial distribution of crimes. Here we are approximating a cumulative distribution function depicting the frequency of incidents at particular distances from the weather station.

behaviour, throwing missiles, or impeding access to communal areas. The data used in this study were coded under a single incident category which could not be broken down into different forms such as those above. It is, however, recognised that if this information were available it would form an interesting extension of the current study, and would provide a more in-depth analysis to assess whether all forms of disorder or disturbance are similarly influenced by weather parameters. It should be noted that for all incidents, unless the incident was directly observed by a patrolling police officer, it was necessary for a member of the public to decide to report it-therefore some incidents may go unrecorded.

In addition to police incident data, we have utilised weather data from a weather station central to the study area. The central location of the weather station is shown in figure 1, which shows that approximately $50 \%$ of the incidents occur within $2000 \mathrm{~m}$ of the weather station and that all incidents occur within $12000 \mathrm{~m}$. The use of data from a single weather station was validated by investigating any possible deviations from the records of a second weather station sited locally. Analysis of hourly records (summarised in table 2) indicated broad similarities between such patterns for the two weather stations for the study time period.

The largest deviation between the two weather stations regarded rainfall, for which there were instances when the central weather station recorded no rain whilst the other recorded rainfall. In addition, there were some differences in the volume of rain falling, the tendency being for the central weather station to receive less rainfall. Given the proximity of the central weather station to the majority of the incidents $(50 \%$ of

Table 2. Summary statistics for the deviation between the two weather stations.

\begin{tabular}{lll}
\hline Variable & Mean & Correlation \\
\hline Rainfall $(\mathrm{mm})$ & 2.27 & 0.38 \\
Wind speed $($ knots & 0.83 & 0.73 \\
Temperature $\left({ }^{\circ} \mathrm{C}\right)$ & 1.01 & 0.95 \\
\hline
\end{tabular}


the incidents within $2000 \mathrm{~m}$ ), this deviation was considered acceptable, and justifies the use of a single central station for this particular study. Variables collected from the central weather station for the subsequent analysis included hourly records for temperature $\left({ }^{\circ} \mathrm{C}\right)$, humidity (\%), windspeed (knots), rainfall ( $\mathrm{mm})$, and wind direction (degrees anticlockwise from north). In total, data were collected for 13711 incidents. Prior to the analysis each incident was first associated with the weather conditions at the time the incident was reported. The time at which the incident occurred was first rounded to the nearest hour and was then appended to the meteorological conditions recorded for that hour. Summary statistics are shown for the nondirectional variables in table 3 .

Table 3. Summary statistics for weather variables.

\begin{tabular}{lccccc}
\hline Variable & Minimum & First quartile & Median & Third quartile & Maximum \\
\hline Rainfall $(\mathrm{mm})^{\mathrm{a}}$ & 0.2 & 0.2 & 0.6 & 1.2 & 12.8 \\
Wind speed $(\mathrm{knots})$ & 0.0 & 4.0 & 7.0 & 10.0 & 26.0 \\
Temperature $\left({ }^{\circ} \mathrm{C}\right)$ & -1.7 & 8.3 & 11.2 & 14.6 & 28.2 \\
Humidity $(\%)$ & 15.0 & 71.0 & 79.0 & 87.0 & 100.0
\end{tabular}

a These figures relate only to nonzero recorded rainfall figures.

\section{Methodology}

The methodology is divided into two sections; the first describes the statistical analyses to determine the significance of each meteorological parameter. The second describes techniques to visualise the information and to identify the form of any patterns that are found to be significant.

\subsection{Statistical analyses}

The aim of the statistical testing is to establish if there is any association between the location of an incident $(x, y)$ and the climatic variable at the time the incident occurred, $C$. If location were a single variable, we could assess the correlation between this and the climatic variables by testing a null hypothesis of zero correlation. However, since it is not, another approach must be used. This is the procedure outlined by Kent (1983) and Joe (1989), which will now be described briefly. Suppose the probability density of an incident occurring at location $(x, y)$ during an hour with a climatic variable (say rainfall) of value $C$ is $\mathrm{f}_{\mathrm{lc}}(x, y, C)$. The marginal probability for location is written $\mathrm{f}_{1}(x, y)$ and that for climate as $\mathrm{f}_{\mathrm{c}}(C)$. If spatial patterns do not depend on climate, then location and climate will be probabilistically independent, and so we can write

$$
\mathrm{f}_{\mathrm{lc}}(x, y, C)=\mathrm{f}_{1}(x, y) \mathrm{f}_{\mathrm{c}}(C) .
$$

For the test of association, then, equation (1) is our null hypothesis. Kent (1983) and later Joe (1989) have proposed the following test statistic for this:

$$
\frac{1}{n} \sum_{i=1, n} \ln \left(\frac{\hat{\mathrm{f}}_{\mathrm{lc}}\left(x_{i}, y_{i}, C_{i}\right)}{\hat{\mathrm{f}}_{1}\left(x_{i}, y_{i}\right) \hat{\mathrm{f}_{\mathrm{c}}}\left(C_{i}\right)}\right) .
$$

Here, the 'hats' on the density functions indicate that they must be estimated from the data. This test statistic is essentially based on estimating the likelihood ratio between the null hypothesis and the more general situation in which equation (1) does not hold. Following Bowman and Azzalini (1997) we used kernel density techniques to estimate the probability density functions, and then evaluated the statistic using a permutation test, where the locations were randomly permuted against the climate variables, and the kernel density estimates were then recomputed 500 times. This was 
equivalent to assuming that, under the null hypothesis, any combination of $(x, y)$ and $C$ pairs was equally likely to occur, given the observed dataset.

Having carried out a test of association, if any such association is found we may then return to visual exploration and to mapping the variation in geographical distribution that is associated with the change in the weather. One approach is to select two values of $C$, say $C_{1}$ and $C_{2}$ and to map the log-likelihood ratio of $\mathrm{f}_{\mathrm{lc}}\left(x, y, C_{1}\right)$ and $\mathrm{f}_{\mathrm{lc}}\left(x, y, C_{2}\right)$. Positive values suggest more events are likely to happen at $(x, y)$ if the climatic value is $C_{1}$, whereas negative values suggest locations are more likely to experience events if the value is $C_{2}$. The choice of $C_{1}$ and $C_{2}$ values could be based on external knowledge (eg typical 'hot' and 'cold' temperatures in the study area), or a number of different pairs could be considered to explore the variability of the observed patterns.

Some methodological issues arise here. Firstly, we are aware that the climatic measurement is based on a single weather station for the whole of the study areaso, for example, although it may be raining near to the weather station, there could be parts of the study area that are still dry. Unfortunately, at the present time there is little we can do to accommodate this. However, since the statistical test is essentially a 'whole-map statistic', a deviation in patterns anywhere on the map should contribute to evidence of association. Thus, it is hoped that, if it were only raining close to the weather station, any deviations in pattern in the region where it was raining would contribute to the statistic. If such local variation in weather does occur, the main effect would be to dilute the local deviations in pattern, and reduce the power of the test. Thus, a rejection of the null hypothesis still suggests an association, but a failure to reject could be attributable to the dilution effect discussed above. This issue may be investigated further by using the mapping approaches outlined above-since the location of the weather station is known, one can identify whether changes in incident patterns are most notable close to the weather station.

The next issue is more technical in nature. Some of the climate variables (such as relative humidity and rainfall) are naturally bounded to lay between a pair of values, $(0,100)$, or to live above a single value, such as zero. Conventional kernel density estimation assumes that no such bounding occurs. To overcome this, we apply the kernel density methodology to transformed data (either taking logarithms or the logit transform) and transform the distribution estimates back afterwards. For humidity, a logit transformation is used, and for wind direction a cosine transformation is used. A related problem occurs with rainfall, in that the underlying phenomenon can be split into two distinct situations:

(1) With probability $p$ it does not rain at all, and total rainfall is zero.

(2) With probability $(1-p)$ it does rain, and total rainfall has a probability distribution which we need to estimate from the data.

To address this, we estimate $p$ empirically from the total number of hours with zero rainfall, against all hours in the study, and then apply the kernel density method only to the nonzero rainfall figures, to get an estimate of $f_{c+}$, the distribution of nonzero rainfall figures. Combining these two results we obtain a new form for $\mathrm{f}_{\mathrm{c}}(C)$ :

$$
\hat{\mathrm{f}}(C)=\left\{\begin{array}{cl}
\hat{p}, & \text { if } C=0 \\
(1-\hat{p}) \hat{\mathrm{f}}_{c+}(C), & \text { otherwise }
\end{array}\right.
$$

Finally, we must allow for the fact that the wind direction bearing is a cyclic variable. Thus wind direction bearings of 010 are in practice close to those of 350 , although these numbers are quite distinct on a linear scale. To overcome this, we create a buffer zone close to bearings of zero, where bearings near to 360 are duplicated as negative bearings (ie a bearing of 350 is duplicated as -10). Similarly, bearings near to zero are 
duplicated as bearings greater than 360 (ie 10 is duplicated as 370). In this way, the kernel smoothing effects are carried over the discontinuity in bearings at due north. Once these adjustments have been made, the same testing procedure as that used for the other variables may be used. Note that for the nonzero rainfall figures, a $\log$ transform is also applied.

In summary, the aim of these tests is to identify whether the spatial patterns observed in the incidence of disorder or disturbance events differ significantly when weather conditions alter. The test statistics here measure the degree to which such differences are observed. Using simulations it is possible to test whether the differences observed are due to random fluctuations in the locations of calls for police service, or whether a genuine connection between calls for police service and weather is being observed. In the next section visualisation approaches will be introduced, allowing the geographical nature of any differences to be investigated.

\subsection{Comap visualisation}

The comap approach (Brunsdon, 2001; Brunsdon et al, 2007) is an extension of Cleveland's (1993) coplot. The concept of each of these approaches is founded on the idea of using 'small multiples' to emphasise variation in pattern (Tufte, 1990). In particular, the coplot is used to examine the relationship between a pair of variables (eg $x$ and $y$ ) and is conditioned on the value of some third variable $(z)$. This permits an investigation of how the relationship between $x$ and $y$ varies, given the value of $z$. In the case of the coplot the output is a panel of scatterplots, in the case of the comap it is a panel of maps (see figure 3 for examples of the comap). Each map window or viewport in the comap is geographically fixed, and therefore each viewport represents the same geographical extent to facilitate more effective comparative analysis between viewports. The scale of the comaps presented in figure 3 from east to west (left to right) is approximately $20 \mathrm{~km}$ in total and represents the entire intraurban region. North is in the direction of the top of each viewport and the city centre is located approximately $12 \mathrm{~km}$ from the west and $5 \mathrm{~km}$ to the north.

In short, the individual maps in the comap are obtained from kernel density estimates of spatial variables. Each set of spatial variables is a subset of the whole dataset, selected so that the conditioning variable lies within a given range. In each map the range is chosen so that each comap panel is based on the same number of data points. For a fuller discussion of the comap approach, including data preprocessing and representation, see Brunsdon (2001).

In this paper the variables $x$ and $y$ correspond to geographical location, and the $z$ variable is a weather parameter, such as rainfall. For reasons of visualisation clarity, a 'risk surface' is created from the $x, y$ data using kernel density estimation (Silverman, 1986). Given the large number of points involved, in addition to their geographic concentration, the use of a point representation would result in a large cloud of points (many positioned over the top of one another), making interpretation difficult.

\section{Discussion}

Incident data used for this analysis are from a database of police callouts to reported acts of disorder or disturbance for an urban centre and its surrounding region for a two-year period. For each police callout, a date, a time, and a grid reference were supplied. The time of day and locational information were used to construct a 'risk surface' via kernel density estimation (Silverman, 1986). Here, the probability density of a callout occurring is a function of location $(x, y)$ and time of day $t$, so that $p=\mathrm{f}(x, y, t)$. Metrological data are hourly readings for a weather centre central to the 


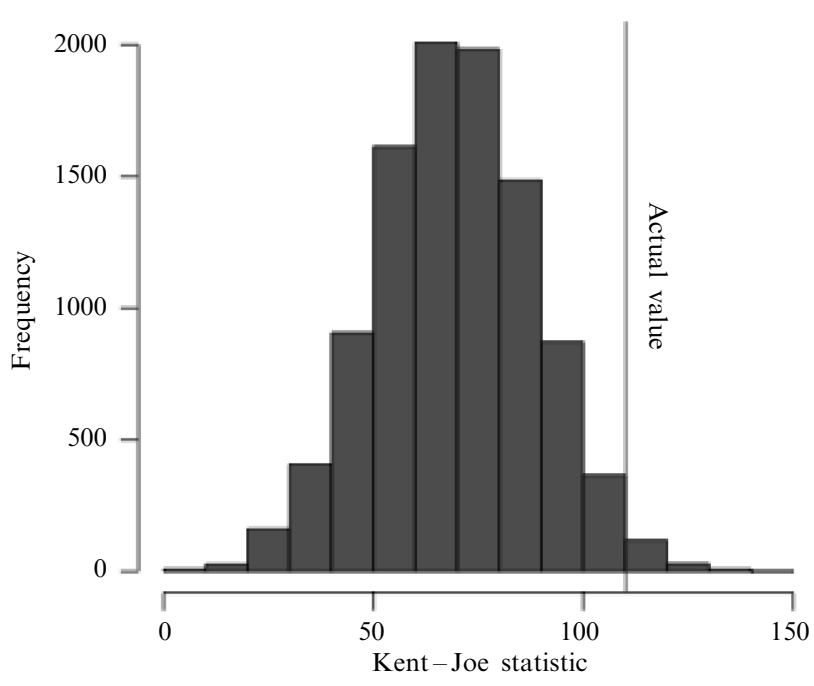

Figure 2. Results of Monte Carlo Kent-Joe statistic test for association between temperature and spatial location of disturbances in the winter months. The histogram shows the experimental distribution. The observed value is indicated by the vertical line.

study area, including temperature $\left({ }^{\circ} \mathrm{C}\right)$, rainfall $(\mathrm{mm})$, wind speed (knots), wind direction, and humidity (\%).

Using the weather data, the mean temperature during the hour in which each incident occurred was identified, and this information was merged with the incident database. From this, incidents occurring between the hours of 8 PM and midnight were selected (a total of 4406 incidents), and were subjected to the statistical test outlined above, in order to investigate evidence of an association between spatial location and temperature. Also, to allow for seasonal effects, the data were split into two subgroups, for summer months (April-September) and winter months (October-March). A permutation Monte Carlo test showed that $p<0.01$ - suggesting that there is sufficient evidence to reject a null hypothesis of no association. This is illustrated in figure 2 , which shows the experimental distribution of the Kent - Joe statistic under a permutation distribution. From this it is clear that the observed value (vertical line on right) is outside of the 'usual' values of the statistic one might expect under a null hypothesis of no association.

Similar tests were carried out on the other variables, with significance levels as in table 4. From this it can be seen that the only variables showing significant association with spatial patterns were temperature and humidity. It is also apparent that these results are the same both for summer and for winter months.

Table 4. Results of the significance tests for each weather variable for winter and summer months.

\begin{tabular}{lllllll}
\hline Season & & Temperature & $\begin{array}{c}\text { Wind } \\
\text { speed }\end{array}$ & $\begin{array}{l}\text { Wind } \\
\text { direction }\end{array}$ & Humidity & Rainfall \\
\hline Winter & $p$-value & 0.00 & 0.21 & 0.47 & 0.00 & 0.46 \\
Summer & $p$-value & 0.01 & 0.29 & 0.07 & 0.03 & 0.15 \\
\end{tabular}


The spatial patterns are shown in the comaps of figures 3(a) and 3(b) (summer months) and figures 3(c) and 3(d) (winter months). From these it may be seen that, at higher temperatures (temperature increases from the lower-right to upper-left panel), there is a greater proportion of incidents occurring outside of the city centre, particularly to the northwest of the city centre in both summer and winter. A similar pattern is seen to occur for humidity. Also, in the summer months, there is a fall-off in incidence in a band between the central area and the northeast when humidity increases.

Perhaps it is rather surprising that rainfall showed no association-one might have expected that the presence or absence of rain would modify an individual's typical routines, affecting their decision to travel outdoors. For example, in a very simplistic scenario a wet night would see a reduction in the number of people travelling to the city centre, therefore one would expect the volume of disorder to be reduced (in comparison to normal levels), coupled with the possibility of elevated levels of disorderly conduct in residential areas. This result of no association is perhaps one of the situations in which the 'dilution effect' discussed earlier may lead to a nonsignificant result. Another possibility is that many of the incidents are triggered inside buildings, and whereas humidity and temperature will affect conditions inside buildings, this is not the case for rainfall. There is perhaps need for a future study in which rainfall data of finer geographical resolution are analysed.

From a theoretical perspective RA theory can successfully be used to justify the results obtained, in that warmer temperatures encourage the greater use of outdoor spaces. In doing so there is a greater convergence in space (and time) of the three fundamental elements (motivated offenders, suitable targets, and absence of capable guardians) necessary for an incident to occur, in this case disorder or disturbance. Taking each of the three elements individually, changes in temperature may be seen to modify their interplay with one another. So, for example, on a cold day people would tend to spend less time outdoors - in comparison with a warm day, on which it is more common to remain outdoors for longer periods of time. In this case the greater use of these outdoor spaces (for example, private gardens, public parks, streets, and open spaces) in warmer weather permits a higher degree of social contact where individuals can partake in activities such as sport or outdoor celebrations. In such cases temperature may be seen to increase the number of motivated offenders through the increased opportunity of using these outdoor spaces - which themselves, being targets, become more suitable in warmer weather, and where there tends to be fewer capable guardians (eg police patrols or CCTV systems) present. With the increased use of these outdoor spaces in warmer weather a higher incidence of disorderly conduct is experienced - for example, drunkenness, playing of loud music, and general noise nuisance. Without further contextual detail in the data, such as the nature of the disorder, age of offender(s), gender, and presence of alcohol, no further conclusions can be drawn. This could, however, form an interesting focus for future research, from which the effect of weather on disorderly behaviour could be more thoroughly examined and more detailed conclusions drawn.

From a T/A theoretical perspective the type of incidence used in this study is not one of aggression and we would need to analyse other incident and crime data (eg an incident database of reported assaults) to draw any conclusions.

From a policing perspective we would suggest that the results reported in the study have the potential to inform the selection of salient variables as part of an early warning crime and incident system to help justify resource allocation decisions or as part of a resource targeting strategy. For example, given that there is a statistically significant and geographically discernable association between disorder or disturbances and temperature, temperature could be added to a spatial forecast model together with other explanatory factors. 
Temperature $\left({ }^{\circ} \mathrm{C}\right)$

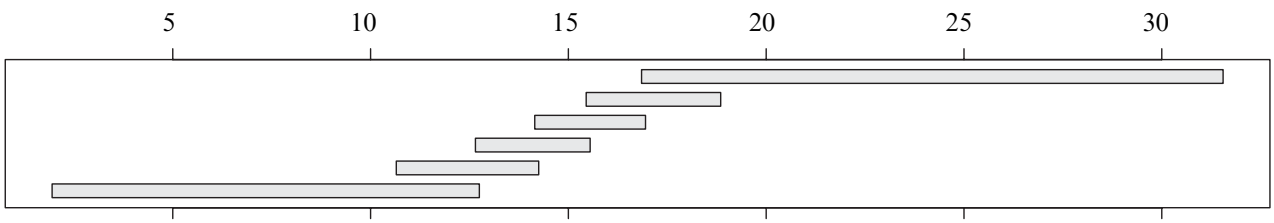
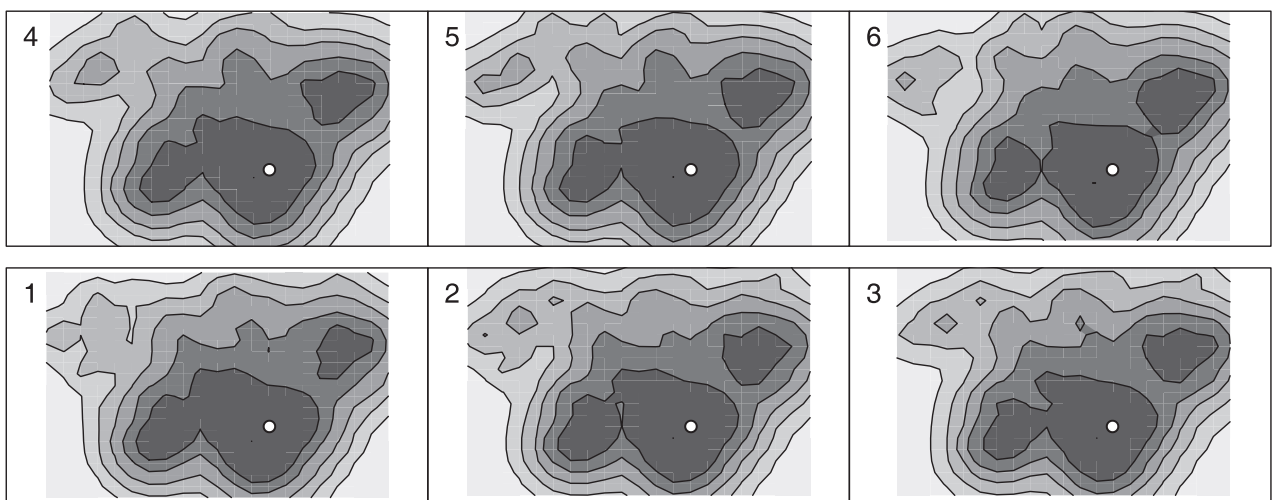

(a)

Relative humidity (\%)

20

40

60

80

100
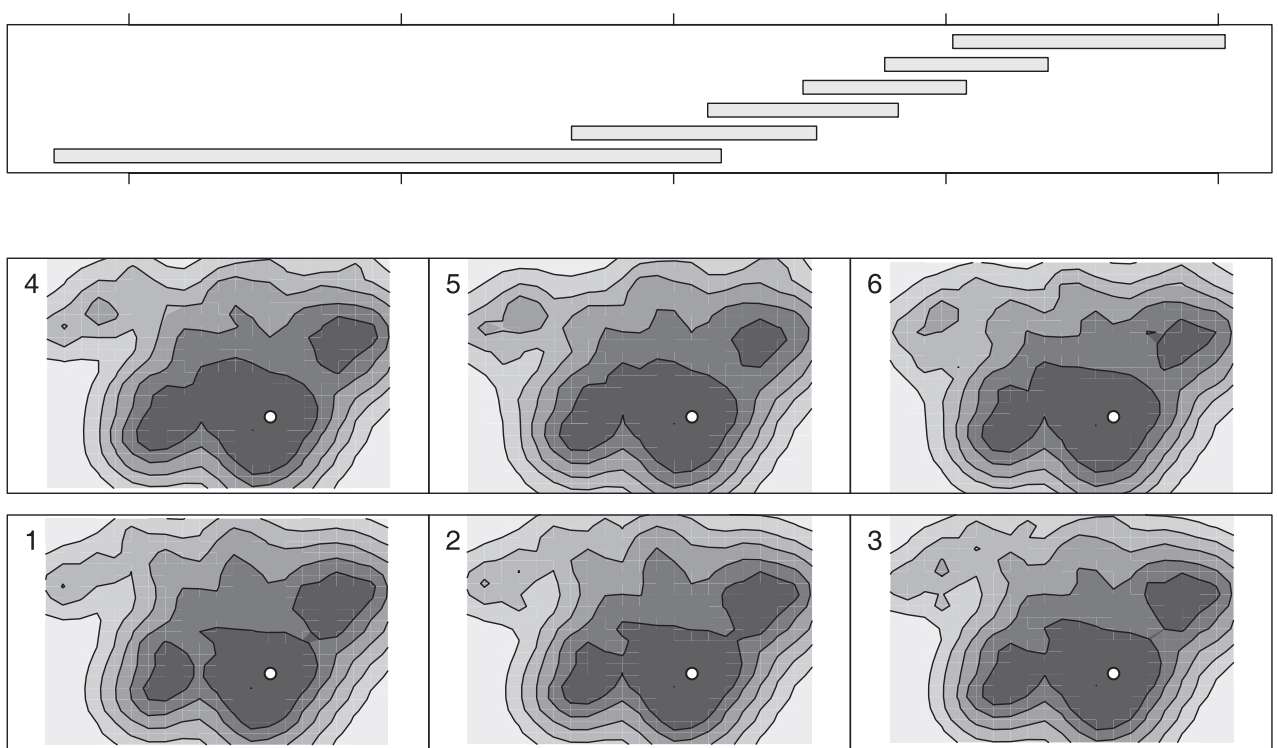

(b)

Figure 3. Comaps showing the distribution of incidents (a) during summer months, conditional upon temperature; (b) during summer months, conditional upon humidity; (c) during winter months, conditional upon temperature; and (d) during winter months, conditional upon humidity. Panels are numbered in terms of increasing covariate. The white dot indicates the central business district. Summer months are defined as April-September; winter months are defined as October-March. 

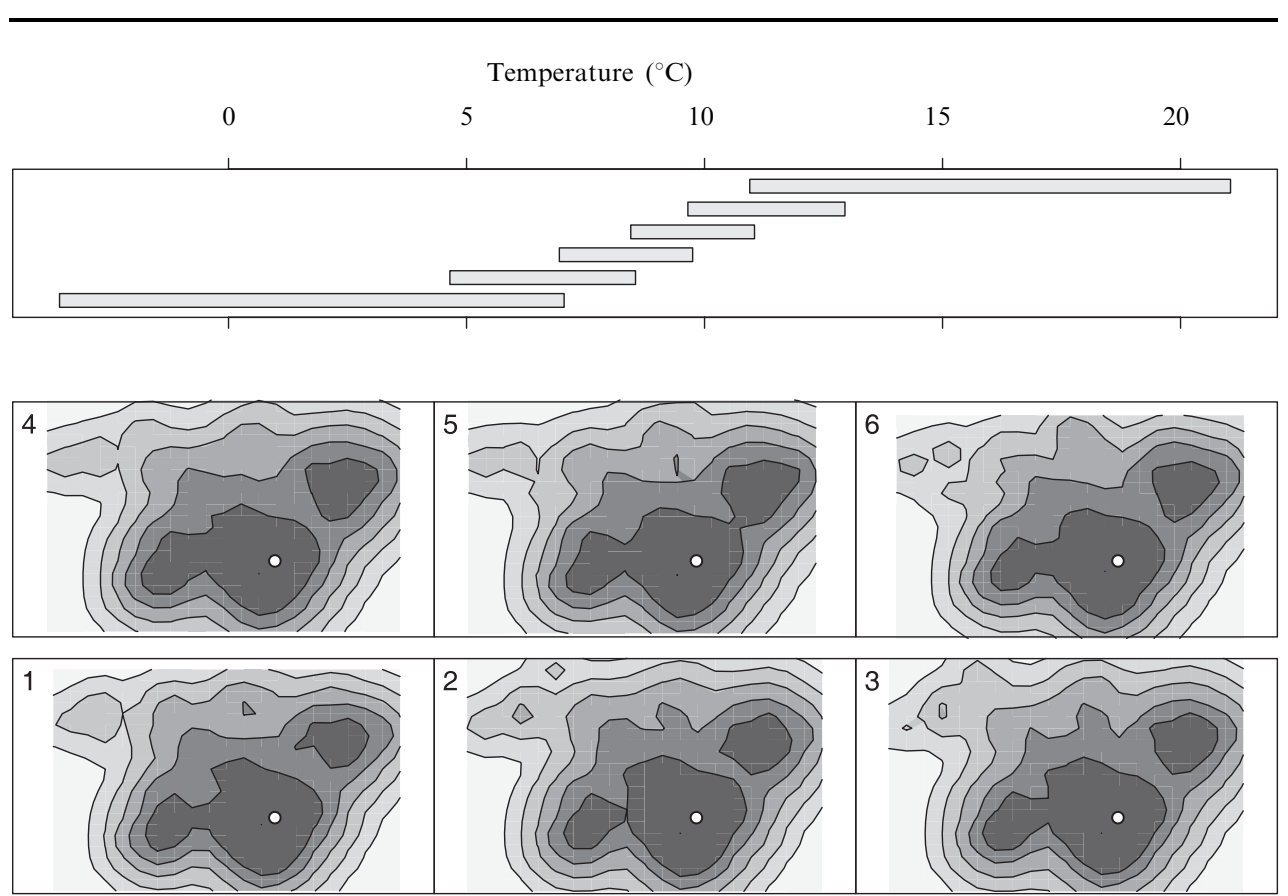

(c)

Relative humidity (\%)

40

60

80

100
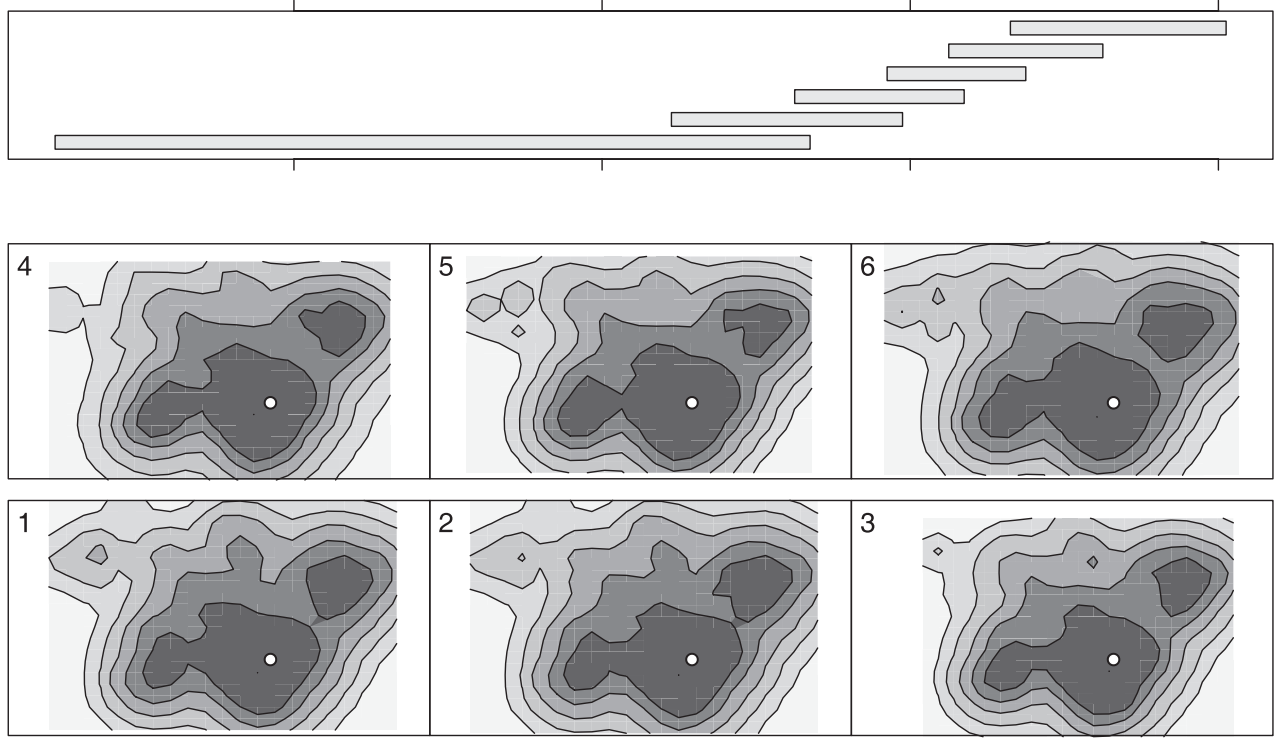

(d)

Figure 3 (continued). 
In this paper we have made advancements in two main areas. Firstly, we used microlevel data to investigate the effect of weather on detailed police incident patterns. Secondly, we applied a novel combination of techniques that have revealed a statistically significant influence of temperature and humidity which was visually inspected using the comap at an intraurban level. There are several areas that warrant further investigation from this preliminary study in order to improve and extend the current methodology and results. Firstly, the use of a single weather station is one element of the analysis that could be improved. Despite the fact that a second weather station located on the western limits of the study area was used to justify the use of a single reading for all incidents across the study region, an ideal situation to ensure accurate assignment of a meteorological parameter to an incident would be an evenly distributed set of weather stations across the study region.

In this study we applied the techniques to a single incident type (disorder or disturbance). In future work this could be extended to other incident or crime types to address questions such as: does temperature have the same effect on the spatial distribution of disorder or disturbances as on that of burglary and criminal damage? However, in order to apply the same techniques as we present in this paper, further work is called for relating to methods of associating a set of weather parameters to individual incidents or crimes (such as burglary), given that the time stamp can be less precise. The answer to addressing this question could lie with the use of lags [for example, aoristic type analysis - see Ratcliffe (2000)]. In addition, we have not examined the relationship between other weather types (eg snowfall) because this is not likely to be a significant factor in the relatively mild winters of the UK but, we suggest, these techniques could be feasibly used to investigate the effects of such variables in regions with different climatic regimes. Finally, future work could supplement the analysis with additional factors, such as the spatial concentration of public houses and other entertainment establishments, and the use of contextual variablesfor example, socioeconomic covariates [as applied in the study by Hipp et al (2004)]. This should form the basis for more detailed qualitative analysis in order to explain observed patterns.

\section{Conclusions}

While the effect of weather on crime patterns has been the focus of a number of studies, with the majority finding that warmer weather is generally associated with more crime and colder conditions associated with fewer such events, such research has tended to be carried out for relatively large geographical areas or for seasonal fluctuations in weather and crime rates. This paper has two main objectives. Firstly, we provide a disaggregate analysis of the relationship between weather parameters and incidences of disorder or disturbance at an intraurban level. Secondly, we demonstrate the use of new statistical and visualisation techniques in order to examine such relationships. This, in turn, has permitted us to draw up appropriate theoretical explanations for such patterns. In common with previous studies that have found significant correlations between high temperatures and violent crime, the results produced here have indicated that both temperature and humidity significantly affect the geography of disorder or disturbances. Some of the studies reviewed above found that precipitation is associated with lower levels of criminal activity. In our study, however, rainfall, wind speed, and wind direction were not found to exert a significant effect, and these findings mirror those of Field (1992) who did not identify any effect of rainfall on crime.

In this paper we have built on a body of research that has applied geographical (spatial) techniques to investigate detailed geographical patterns in calls for police service. 
Specifically we have successfully applied a novel combination of techniques that is capable of both evaluating statistically and visualising geographically the effect of weather on police incidents, using datasets that are routinely collected by police forces and meteorological organisations. In this case we have been interested in applying such techniques to police callouts for disorder or disturbance. Clearly, our conclusions at this stage therefore are tentative and we suggest that more research is needed to explore the use of such techniques in relation to other types of incident or crime and in other geographical areas with larger variations in climatic conditions to see if these findings are replicated in other contexts.

Finally, whilst there have been important developments in extending the range of spatial analytical functionality available in proprietary GIS packages in the last decade, and GIS has been used extensively in our current research, it should be reiterated that much of the analysis presented in this paper has used techniques that are not routinely available to crime-mapping professionals. By demonstrating the benefits of extending such functionality, we hope that we have showed the advantages of incorporating new techniques in any research initiatives in the field of crime pattern analysis.

Acknowledgements. We wish to thank the UK Meteorological Office for the provision of the weather data used in this paper.

\section{References}

Anderson C A, Anderson D C, 1984, "Ambient temperature and violent crime - tests of linear and curvilinear hypotheses" Journal of Personality and Social Psychology 4691 -97

Anderson C A, Bushman B J, Groom R W, 1997, "Hot years and serious and deadly assault: empirical tests of the heat hypothesis" Journal of Personality and Social Psychology $731213-1223$

Anonymous, 1910, "Crime and the weather" The Lancet 1751360 - 1361

Anselin L, 1995, "Local indicators of spatial association-LISA" Geographical Analysis 2793 - 115

Anselin L, 2004, "Review of cluster analysis software", http://www.naaccr.org/filesystem/pdf/ Final\%20Report\%20Cluster\%20Software\%202004-09-27\%20rev.pdf

Anselin L, Cohen J, Cook D, Gorr W, Tita G, 2000, "Spatial analyses of crime" Criminal JusticeMeasurement and Analysis of Crime and Justice 4231 - 262

BBC News, 2001, "Summer 'seeks peak in violence"," http://news.bbc.co.uk/1/hi/health/1182636.stm BBC News, 2003a, "Heat wave sparks car break-ins", http://news.bbc.co.uk/1/hi/wales/3173453.stm

BBC News, 2003b, "Warning over warm weather robberies", http://news.bbc.co.uk/1/hi/england/ northamptonshire/3030282.stm

Boba R, 2005 Crime Analysis and Crime Mapping (Sage, Beverly Hills, CA)

Bowers K, Hirschfield A, 1999, "Exploring links between crime and disadvantage in north-west England: an analysis using geographical information systems" International Journal of Geographical Information Science $13159-184$

Bowers K, Johnson S D, Pease K, 2004, "Prospective hot-spotting: the future of crime mapping?" British Journal of Criminology 44641 - 658

Bowman A W, A Azzalini, 1997 Applied Smoothing Techniques for Data Analysis (Oxford University Press, Oxford)

Brantingham P L, Brantingham P J, 1993, "Environment, routine, and situation: toward a pattern theory of crime", in Routine Activity and Rational Choice volume 5, Eds R V Clarke, M Felson (Transaction, New Brunswick, NJ) pp 259-294

Brunsdon C, 2001, "The comap: exploring spatial pattern via conditional distributions" Computers, Environment and Urban Systems $2553-68$

Brunsdon C, Corcoran J, Higgs G, 2007,"Visualising space and time in crime patterns: a comparison of methods" Computers, Environment and Urban Systems 31 52-75

Canter P R, 1998, "Geographic information systems and crime analysis in Baltimore County, Maryland", in Crime Mapping and Crime Prevention volume 8, Eds D Weisburd, J T McEwen (Criminal Justice Press, Monsey, NY) 157 - 190

Ceccato V, 2005, "Homicide in São Paulo, Brazil: assessing the spatial-temporal and weather variations" Journal of Environmental Psychology 25 307-321 
Chainey S, 2002, "New perspectives and developments in crime mapping: from blobology and better partnership working, to crime science and supporting serious crime investigations", paper presented at the Sixth Annual International Crime Mapping Research Conference, Denver, CO, http://www.ojp.usdoj.gov/nij/maps/Conferences/ozconf/Papers\&Presentations.html

Chainey S, Ratcliffe J H, 2005 GIS and Crime Mapping (John Wiley, New York)

Chainey S, Reid S, Stuart N, 2002, "When is a hotspot a hotspot? A procedure for creating statistically robust hotspot maps of crime", in Socio-economic Applications in Geographical Information Science Eds D B Kidner, G Higgs, S D White (Taylor and Francis, London) pp $21-36$

Cheatwood D, 1995, "The effects of weather on homicide" Journal of Quantitative Criminology $1151-70$

Clark P J, Evans F C, 1954, "Distance to the nearest neighbour as a measure of spatial relationships in populations" Ecology $35445-453$

Cleveland W S, 1993 Visualizing Data (Hobart Press, Lafayette, IN)

Cohen L E, Felson M, 1979, "Social change and crime rate trends: a routine activity approach" American Sociological Review $44588-608$

Cohn E G, 1990, "Weather and crime" British Journal of Criminology 3051 - 63

Cohn E G, 1993, "The prediction of police calls for service: the influence of weather and temporal variables on rape and domestic violence" Journal of Environmental Psychology 13 71-83

Cohn E G, 1996, "The effect of weather and temporal variations on calls for police service" American Journal of Police 1523 - 43

Cohn E G, Rotton J, 1997, "Assault as a function of time and temperature: a moderator-variable time series analysis" Journal of Personality and Social Psychology $721322-1134$

Cohn E G, Rotton J, 2000, "Weather, seasonal trends and property crimes in Minneapolis, 1987 - 1988: a moderator-variable time-series analysis of routine activities" Journal of Environmental Psychology $20257-272$

Corcoran J, Ware J A, 2002, "Helping with enquiries" Geo: Connexion 136 - 40

Cornish D B, Clarke R V (Eds), 1986 The Reasoning Criminal: Rational Choice Perspectives on Offending (Springer, New York)

Cotton J L, 1986, "Ambient temperature and violent crime" Journal of Applied Social Psychology $16786-801$

Davis R E, Knappenberger P C, Michaels P J, Novicoff W M, 2004, "Seasonality of climate - human mortality relationships in US cities and impacts of climate change" Climate Research $\mathbf{2 6} 61-76$

Eck J E, Weisburd D L (Eds), 1995 Crime and Place: Crime Prevention Studies (Criminal Justice Press, Monsey, NY)

Feldman H S, Jarmon R G, 1979, "Factors influencing criminal behavior in Newark: a local study in forensic psychiatry" Journal of Forensic Science $24234-239$

Field S, 1992, "The effect of temperature on crime" British Journal of Criminology 32340 - 351

Gatrell J D, Bierly G D, 2002, "Weather and voter turnout: Kentucky primary and general elections, 1990 - 2000" Southeastern Geographer 42114 - 134

Geary R, 1954, "The contiguity ratio and statistical mapping" The Incorporated Statistician $\mathbf{5}$ $115-145$

Goldsmith V, McGuire P G, Mollenkopf J B, Ross T A (Eds), 2000 Analyzing Crime Patterns: Frontiers of Practice (Sage, Beverly Hills, CA)

Guerry A M, 1833 Essai sur la statistique morale de la France (Crochard, Paris)

Hagelin J S, Rainforth M V, Orme-Johnson D W, Cavanaugh K L, Alexander C N, Shatkin S F, Davies J L, Hughes A O, Ross E, 1999, "Effects of group practice of the transcendental meditation program on preventing violent crime in Washington DC: results of the National Demonstration Project, June - July 1993” Social Indicators Research 47 153-201

Harries K, 1999 Mapping Crime: Principle and Practice (National Institute of Justice, Washington, DC)

Harries K D, Stadler S J, Zdorkowski R T, 1984, "Seasonality and assault: explorations in interneighbourhood variation, Dallas, 1980" Annals of the Association of American Geographers $74590-604$

Heller N B, Markland R B, 1970, "A climatological model for forecasting the demand for police service" Journal of Research in Crime and Delinquency 7 167-176

Hipp J R, Bauer D J, Curran P J, Bollen K A, 2004, "Crimes of opportunity or crimes of emotion? Testing two explanations of seasonal change in crime" Social Forces 821333 - 1372

Hirschfield A, Bowers K, 1997, "The development of a social demographic and land use profiler for areas of high crime" British Journal of Criminology 37 103-120 
Hirschfield A, Bowers K (Eds), 2001 Mapping and Analysing Crime Data: Lessons from Research and Practice (Taylor and Francis, London)

Home Office, 2005 Crime Mapping: Improving Performances-A Good Practice Guide for Front Line Officers (Home Office, London)

Joe H, 1989, "Relative entropy measures of multivariate dependence" Journal of the American Statistical Association $84157-164$

Johnson H, Kovats R S, McGregor G, Stedman J, Gibbs M, Walton H, Book L, Black E, 2005, "The impact of the 2003 heat wave on mortality and hospital admissions in England" Health Statistics Quarterly 256 - 11

Kent J T, 1983, "Information gain and a general measure of correlation" Biometrika $70163-173$

Kovats R S, Hajta S, Wilkinson P, 2004, "Contrasting patterns of mortality and hospital admissions during hot weather and heat waves in Greater London, UK" Occupational and Environmental Medicine $61893-898$

Kulldorff M, 1997, "A spatial scan statistic" Communications in Statistics: Theory and Methods $261481-1496$

Lab S P, Hirschel J D, 1988, "Climatological conditions and crime: the forecast is...?”Justice Quarterly $5281-299$

Langworthy R H, Jefferis E S, 2000, "The utility of standard deviation ellipses for evaluating hot spots", in Analyzing Crime Patterns-Frontiers of Practice Ed. T A Ross (Sage, Beverly Hills, CA) pp $87-104$

LeBeau J L, Corcoran W T, 1990, "Changes in calls for police service with changes in routine activities and the arrival and passage of weather fronts" Journal of Quantitative Criminology $6269-291$

Leipnik M R, Albert D P (Eds), 2003 GIS in Law Enforcement: Implementation Issues and Case Studies (Taylor and Francis, London)

McLafferty S, Williamson D, McGuire P G, 2000, "Identifying crime hot spots using kernel smoothing", in Analyzing Crime Patterns-Frontiers of Practice Ed. T A Ross (Sage, Beverly Hills, CA) pp $77-85$

Mamalian C A, LaVigne N G, 1999, "The use of computerised crime mapping by law enforcement: survey results" National Institute of Justice Research Preview

Moran P A P, 1950, "Notes on continuous stochastic phenomena" Biometrika 37 17-23

Murray A T, McGuffog I, Western J S, Mullins P, 2001, "Exploratory spatial data analysis techniques for examining urban crime" British Journal of Criminology 41309 - 329

Openshaw D, Waugh D, Cross A, 1994, "Some ideas about the use of animation as a spatial analysis tool", in Visualization in Geographic Information Systems Eds H M Hearnshaw, D J Unwin (John Wiley, New York) pp $131-138$

Patz J A, Engelberg D, Last J, 2000, "The effects of weather on public health" Annual Review of Public Health $21271-307$

Perry J D, Simpson M E, 1987, “Violent crimes in a city: environmental determinants” Environment and Behaviour $1977-90$

Preti A, 1997, "The influence of seasonal change on suicidal behaviour in Italy" Journal of Affective Disorders 44123 - 130

Quètelet M A, 1842 A Treatise on Man and the Development of his Faculties English translation (Burt Franklin, New York)

Ratcliffe J H, 2000, "Aoristic analysis: the spatial interpretation of unspecific temporal events" International Journal of Geographical Information Science 14669 -679

Ratcliffe J H, 2002, "Aoristic signatures and the spatio-temporal analysis of high volume crime patterns" Journal of Quantitative Criminology 1823 - 43

Ratcliffe J H, 2004, "The hotspot matrix: a framework for the spatio-temporal targeting of crime reduction" Police Practice and Research 5 5-23

Ratcliffe J H, 2005, "Detecting spatial movement of intra-region crime patterns over time" Journal of Quantitative Criminology 21103 - 123

Rogerson P, Sun Y, 2001, "Spatial monitoring of geographic patterns: an application to crime analysis" Computers, Environment and Urban Systems 25539 - 556

Rotton J, 2004, "Outdoor temperature, climate control and criminal assault - the spatial and temporal ecology of violence" Environment and Behavior 36 276-306

Rotton J, Cohn E G, 2000a, "Weather, disorderly conduct and assaults-from social conflict to social avoidance" Environment and Behavior 32 651-673

Rotton J, Cohn E G, 2000b, "Violence is a curvilinear function of temperature in Dallas: a replication" Journal of Personality and Social Psychology 78 1074-1081 
Rotton J, Cohn E G, 2002, "Climate, weather and crime", in The New Handbook of Environmental Psychology Eds R Bechtel, A Churchman (John Wiley, New York) pp 461 -498

Rotton J, Cohn E G, 2003, "Global warming and US crime rates - an application of routine activity theory" Environment and Behavior $35802-825$

Rotton J, Cohn E G, 2004, "Outdoor temperature, climate control and criminal assault: the spatial and temporal ecology of violence" Environment and Behaviour 36 276-306

Rotton J, Frey J, 1985, "Air pollution, weather, and violent crimes: concomitant time-series analysis of archival data" Journal of Personality and Social Psychology 491207 - 1220

Sherman L W, Gartin P R, Buerger M E, 1989, "Hot spots of predatory crime: routine activities and the criminology of place" Criminology $2727-55$

Silverman B W, 1986 Density Estimation for Statistics and Data Analysis (Chapman and Hall, London)

Sulman F G, 1984, "The impact of weather on human health" Review of Environmental Health 4 $83-119$

Tufte E R, 1990 Envisioning Information (Graphics Press, Cheshire, CT)

Van Koppen P J, Jansen R W J, 1999, "The time to rob: variation in time of number of commercial robberies" Journal of Research in Crime and Delinquency 36 7-29

Weisburd D, McEwen J T, 1995 Crime Mapping and Crime Prevention (Criminal Justice Press, Monsey, NY)

Yan Y Y, 2004, "Seasonality of property crime in Hong Kong” British Journal of Criminology 44 $276-283$

Zacharias J, Stathopoulos T, Wu H, 2001, "Microclimate and downtown open space activity" Environment and Behaviour $33296-315$ 
Conditions of use. This article may be downloaded from the E\&P website for personal research by members of subscribing organisations. This PDF may not be placed on any website (or other online distribution system) without permission of the publisher. 